\title{
Wireless Sensor Network Based Irrigation Management System
}

\author{
Associate Prof.B.T.Salokhe ${ }^{1}$, Miss Shilpa G. Gadekar ${ }^{2}$ \\ M.E, Electronics, T.K.I.E.T, Warnanagar, India ${ }^{1}$ \\ B.E, Electronics, T.K.I.E.T, Warnanagar, India ${ }^{2}$
}

\begin{abstract}
Irrigation plays an important role in crops production. Irrigation procedures are based on farmer's experience, soil properties and environmental conditions that are affected by changes in environmental conditions but these procedures are labor expensive, time consuming and wastage of the resources because it requires regular visits and attention. Therefore, adaption of technology is necessary for efficient utilization and saving of fresh water. Wireless sensor network is desirable solution for automating irrigation procedures, efficient utilizations of water and yield production etc. It presents an irrigation scheduling mechanism for the farmers having fewer resources that can be followed during four different seasons. In this paper, an effective irrigation management system is presented for various crops. It utilizes wireless sensor network for obtaining soil properties and environmental data continuously. Irrigation schedule of different plants is planned according to their requirement which is based on the data obtained from sensor nodes deployed at different locations.
\end{abstract}

Keywords: Wireless sensor networks (WSN), Environmental parameters, Container grown crops, Zigbee, Irrigation management system (IMS).

\section{I.INTRODUCTION}

Agriculture is one of the most ancient activities of man in and cost-effective solution to many embedded control which innovation and technology are usually accepted applications [4].

with difficulty, unless real and immediate solutions are found for specific problems or for improving production and quality. Nevertheless, a new approach of gathering information from the environment could represent an important step towards high quality and eco-sustainable agriculture [1].

Activities in agriculture sector are carried out through traditional manual procedures that are time consuming and labor expensive. The crops quality and production rate is improved by providing right resources at right the time in presence of suitable environmental conditions.

Different methods are adopted for collecting environmental and soil related information such as temperature, air humidity, wind direction, soil moisture, $A$. rain detection and soil temperature [2].

Due to advancement in technology the cost and size of sensors is reduced. Wireless sensor network consists of low cost, low powered and multifunctional sensor nodes capable of sensing its surrounding phenomenon wirelessly using Zigbee [3], and The ATmega16 is a 40 pin and lowpower CMOS 8-bit microcontroller based on the enhanced RISC (Reduced Instruction Set Computer) architecture. There are 32 I/O (input/output) lines which are divided into four 8-bit ports designated as PORTA, PORTB, PORTC and PORTD. ATmega16 has various inbuilt peripherals like USART (Universal Synchronous Asynchronous Transmitter), ADC (Analog Digital Convertor), Analog Comparator, etc. Each I/O pin has an alternative task related to in-built peripherals ATmega16 is a powerful microcontroller that provides a highly-flexible

The importance of optimized and efficient irrigation management system development has become the need of time especially the irrigation system that takes decisions over crop's soil, water contents and other environmental parameters. The irrigation management system separates temperature, air humidity and soil moisture values and checks it against their defined threshold values. If the threshold values are crossed, it activates the alarming unit and sends a message via LAN (Local Access Network) [5].

\section{II.PROPOSED WORK \\ IRRIGATION MANAGEMENT SYSTEM (IMS)}

The proposed irrigation system is used for controlling irrigation schedules of various crops. The irrigation schedule is based on temperature, air humidity and soil moisture values obtained from sensor nodes deployed at different locations in the field.

The data is analysed by irrigation management system for further actions. The hardware unit consists of agriculture sensor board specially designed for handling different agriculture activities. It supports many sensors at the same time and switches to different operational modes.

Automatic control of irrigation mechanism requires regular monitoring of different parameters 24 hours/7 days a week. For this purpose, agriculture sensor boards are deployed at three different locations. In early stages of experimental setup, each node was communicating directly with gateway. But for covering more area, one of 


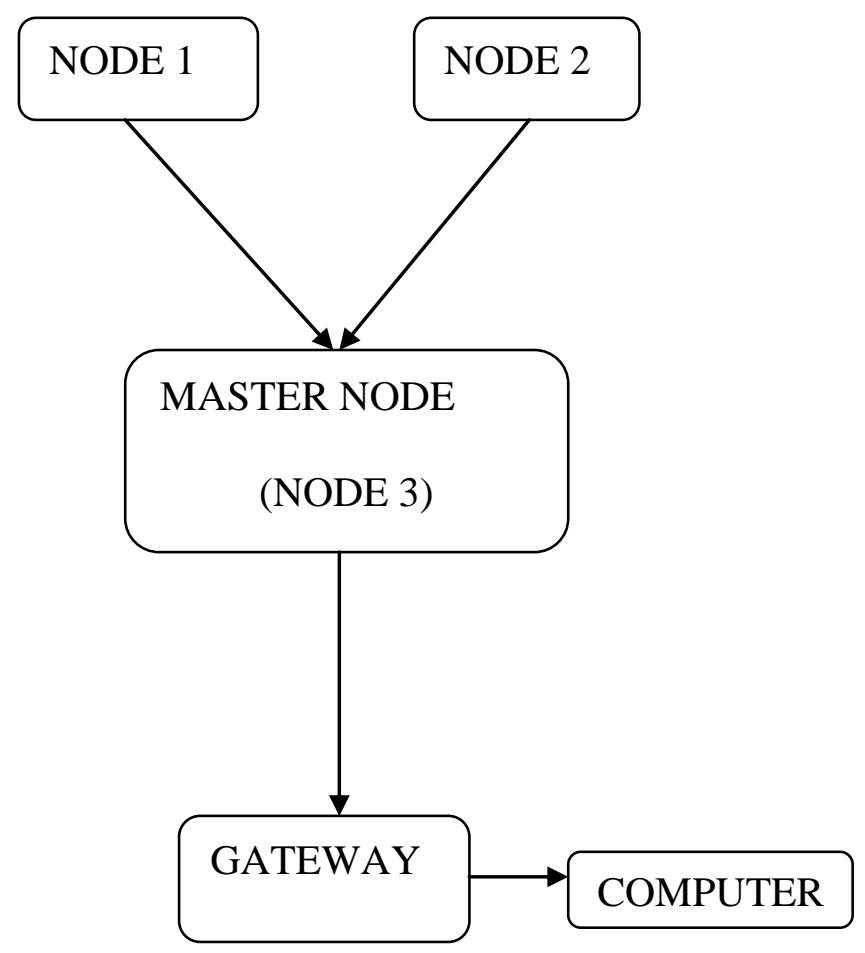

Fig.1. WSN for irrigation management system.

them is working as a relay node in addition to its own for other nodes because they are not within the specified communication range. The design of experimental setup is shown in Fig.1.

The other two nodes are deployed at distance of few meters from Node 3 (master node). The distance between nodes and gateway is kept low in order to reduce packet losses.

Node1 and Node2 send their packets to Node3 because they are unable to communicate directly with gateway. By investigating the destination address Node3 (master node) forward these packets to gateway without making any changes in it. The gateway acts as a bridge between sensor nodes and PC. The data is received in PC via a defined serial port. The irrigation management system checks the received data for any vulnerable condition and inform farmer on LCD display and via alarms.

The block diagram of node 1 and 2 are identical is shown in figure 2.The various sensor information such as temperature, humidity, soil moisture etc is given to ADC of the controller which will be compared with the set threshold values and appropriate actions are taken.

For instance if the temperature is increased then the fan turns on and also this error will be displayed on the LCD of the respective node. The data from node 1 and node 2 is transmitted to Zigbee via UART and finally it is transmitted to master node using RS232. Thus the overall information from master node is transmitted to PC.

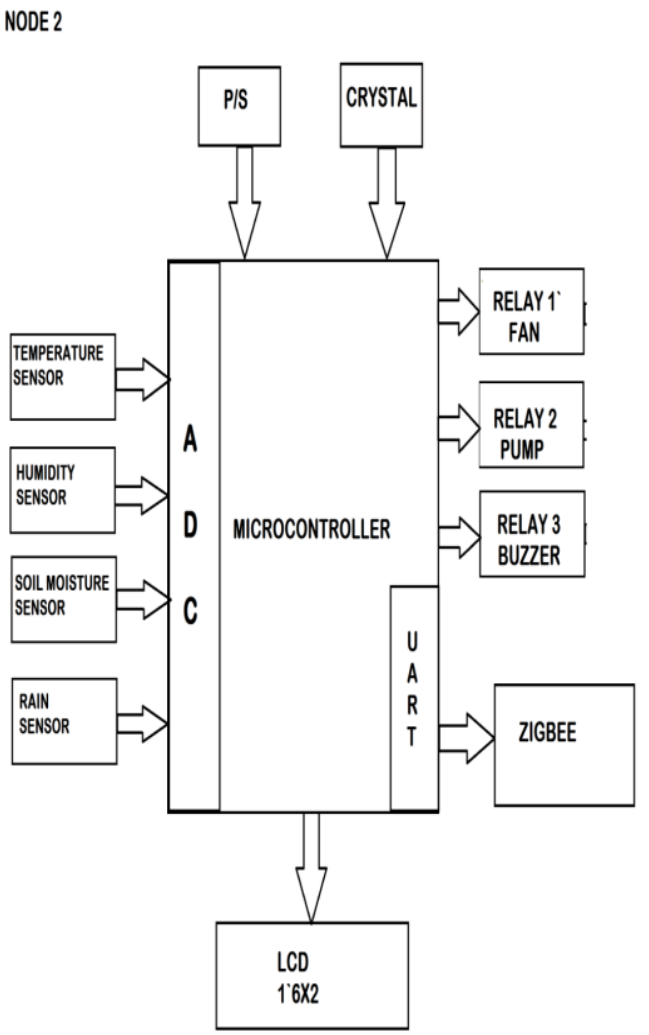

Fig.2. Block diagram of Node 1 and 2.

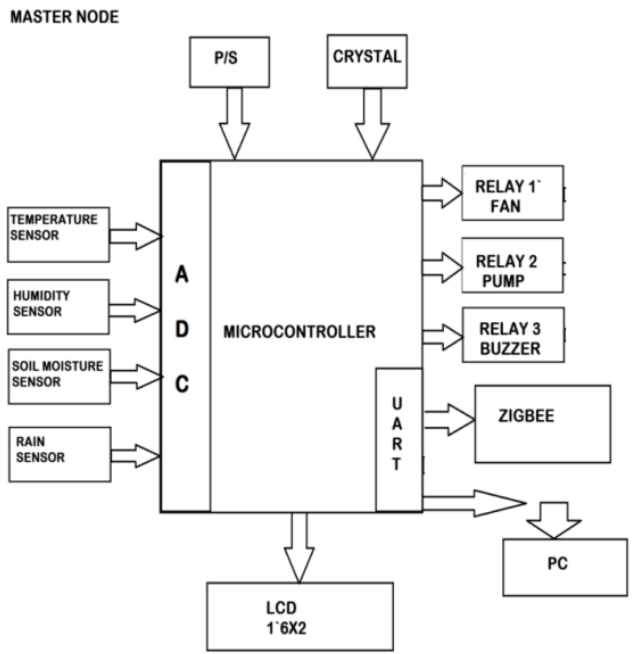

Fig.3. Block diagram of Master Node.

\section{III.CONCLUSION}

Water resources are becoming scares in many countries for the last several years. The importance of optimized and efficient irrigation management system development has become the need of time especially the irrigation system that takes decisions over crops, soil, water contents and other environmental parameters.

Different nodes are used to sense temperature, air humidity and soil moisture after a defined interval of time and sent it to a central location via gateway. The irrigation management system separates temperature, air 
humidity and soil moisture values from each packet and check it against their defined threshold values. If the threshold values are crossed it activates the alarming unit and sent a message via LAN.

\section{ACKNOWLEDGMENT}

I whole heartedly render my gratitude to Tatatyasaheb Kore Institute Of Engineering And Technology, Warnanagar for creating the spirit of technical education. I owe a debt of deepest gratitude to my guide Prof. B.T.Salokhe, for his guidance, support, motivation, and encouragement.

\section{REFERENCES}

[1] Davide, D.P., C. Giovanni, M. Antonio,M. Gianfranco and B. Luca, 2010. "Wireless Sensor Networks for On-Field Agricultural Management Process".In: Geoff VM, Yen K T, editiors.WirelessSensor Networks Application-Centric design, $2^{\text {nd }}$ ed.: In Tech. Publ., pp: 1-18.

[2] Santiago, Jimenez, Pablo Lozada, Cristhy Jimenez and Alejandra Jimenez., 2012. "Wireless Sensors Network in the Efficient Management of Greenhouse Crops".In: Proceeding of 2012 Ninth International Conference on Information Technology- New Generations, Las Vegas. pp: 680-685.

[3] Maxim Osipov "Home Automation with Zigbee". Next GenerationTelegraphic and sWired/Wireless Advanced Networking $8^{\text {th }}$ International Conference, NEW2AN and 1st Russian Conference on Smart Spaces, SMART 2008 St. Petersburg, Russia, September 3-5,2008.

[4] Data sheet of AMEGA16.

[5] "Wireless Sensor Network Based Irrigation Management Systemfor Container Grown Crops in Pakistan" Rahim Khan, Ihsan Ali, M. AsifSuryani, Mushtaq Ahmad and 2Muhammad Zakarya.1.Faculty of Computer Science and Engineering,GIK Institute of Engineering Sciences and Technology, Topi, KPK, Pakistan.2.Department of Computer Science, Abdul Wali Khan University, Mardan. 